\section{Deception beyond measure}

\author{
C.R.B. Joyce
}

False Prophets: Fraud and Error in Science and Medicine. By Alexander Kohn. Basil Blackwell: 1986. Pp.221. $£ 14.95$. To be published in the United States in January 1987, \$24.95.

As THIs book and its chief rival, William Broad and Nicholas Wade's Betrayers of the Truth* both remind us, Charles Babbage distinguished three unorthodox ways of dealing with data. These he called, in increasing order of impropriety, trimming, cooking and forging. Are such behaviours more common today than they were in Babbage's time? In his very first sentence Alexander Kohn states that the exponential growth of science has been accompanied by the "appearance" of deviant scientists, as if a rectilinear growth would not have given rise to the problem. It is not clear whether he thinks that there has been an increase in the number of such individuals, as Broad and Wade imply; and, if so, whether this is absolute or proportional. In fact, there have been more attempts than Kohn realizes to answer the question, but it is not an easy one to tackle, requiring as it does methods learnt from the confessional, the KGB and Social Audit. But whether or not the wickedness has increased or is increasing, we are sure that it should be diminished.

When a question arises in the science of science (a respectable discipline, the methods of which have been successfully applied to the growth of science as a whole), one would expect scientists to try to answer it scientifically. Too often, however, they fall back on dogmatic or wistful assertions of belief. If public attitudes to science were still as starry-eyed as they were even 25 years ago, such piety might suffice. But reassurances that there is nothing to worry about - because the scientific process is self-corrective, and that mistakes, deliberate or accidental, will be found out sooner rather than later - are no longer enough. Such reasoning belongs to the "tap-dancing and dinosaurs" class ("I'm tap-dancing to keep the dinosaurs away!". "But there haven't been any dinosaurs for years!". "There! You see?"). That the only examples of fraud that have been discovered are the ones that have been discovered is not like*Published in 1983 by Simon \& Schuster, and reviewed in Nature 302, 774 (1983). ly to convince the critics of science, and should not satisfy scientists either. Even Popper considers only that errors are "fairly often, in time, corrected".

How much time is needed for the purpose? Seventeen years or so between deed and discovery in the case of Cyril Burt, or 40 for the Piltdown hoax or Gregor Mendel? There are even more important questions to ask about the ethics of scientific discovery than this, but they are seldom examined systematically. One obvious framework is: What is scientific fraud (definitions)? How much of it is there (estimates, including trends)? Why does it occur (reasons - social as well as individual)? Does it matter anyway (costs and possible benefits: see below)? And what is being and should (or can) be done about it?

\section{TRICKS OF THE TESTING TRADE}
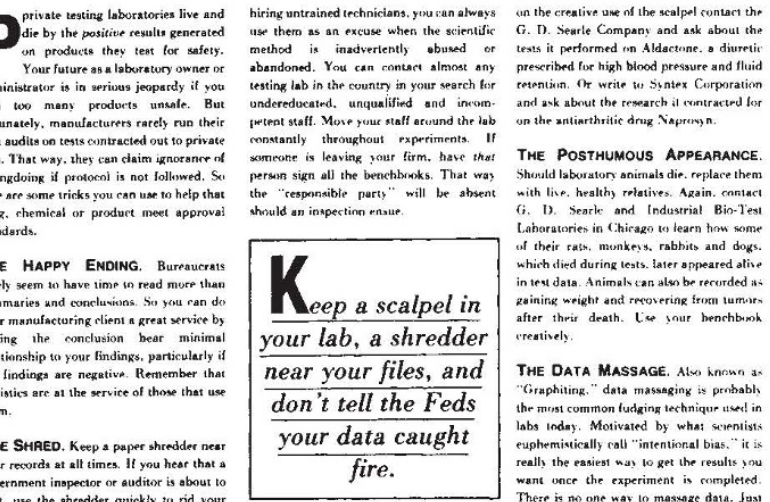

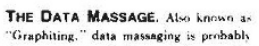
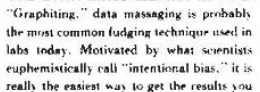

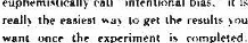

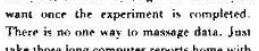
take those lang computer reports home with

THE SPEedup (OR THE TIME-LIN THE SPEEDUP (OR THE TME.LNE
FUDGE. Many Solely teata require lang and kenty apply, rubber and graphis. SOME EXTra ADVICE: II the salidity

scientific fraud would begin, instead of nding, at that point. Given one society Britain) in which the world's largest dvertising agency can switch from helpa national health campaign to promotvery product whose use it had preear; a third (the Soviet Union) in which. . . . The list can be continued to (inity.

One should not, of course, criticize an uthor for writing the book he wanted to rite; but it is fair to suggest that Kohn has ot carried out his own expressed intenon. His sub-title is Fraud and Error in cience and Medicine, less alarmist than road and Wade's Fraud and Deceit in he Halls of Science more open-minded too. It also allows Kohn to mention Mendel and Newton more properly in his book than Broad and Wade in theirs. But though with these references, as well as elsewhere (for example, in the attractive dust-jacket of Wyck's "Alchemist") Kohn implies that error may sometimes be only an idea whose time has not yet come, the theme nowhere receives the discussion its importance requires and the title of the book promises: When is an error not an error but a flash of inspiration? Not only do our hypotheses depend upon our perceptions, but perception is itself a prisoner of hypothesis. Even good scientists have sometimes been so sure that they were right that, in Alan Franklin's words, they "manufactured data .... until real data became available" - even one of Dar-

Of course, Kohn is aware of these problems but, as is common among popularizers of science, he seems to believe that readers prefer a stream of hair-raising stories to a serious discussion of ways to identify and prevent fraud in the future. Thus it would serve little purpose to quote the table of contents; the divisions between subject areas often seem to be arbitrary and the chapter titles usually promise more than the text delivers. Even though his final chapter is entitled "What Can Be Done about Fraud in Science?", and might have been expected to bring together and add to suggestions scattered about the book, it is only three pages long and one of them is taken up by introducing two further anecdotes warning would-be whistle-blowers that theirs is a very chancy and perhaps even dangerous activity.

The most relevant point is made in the very last paragraph of all: "To understand deceit in science, one has to study first the ethics of the society within which the scientists work and live . ..”. A useful book see's retracted papers has already been de-retracted!

Perhaps Kohn fails to deliver because, understandably, he is as uncertain about the matter as the rest of us. In fact, he is at times so uncertain in his handling of certainty in general - for example, the meaning of correlation, and the relationship of truth to the laws of chance; not to speak of his confusion between experimenter (or cognitive) error and experimental (or statistical) error - that the reader is sometimes driven to doubt his grasp of the matters of which he writes.

According to Stephen Toulmin, "medicine has saved the life of ethics" (Perspectives in Biology and Medicine 25, 736-750; 1982 ), producing "spectacular and irreversible effects on the methods and content of philosophical ethics". It is high time for at least a first instalment towards repayment of the debt.

C.R.B. Joyce is Head of Project Innovation in the Medical Department of Ciba-Geigy Ltd, CH-4002 Basel, Switzerland. 